\title{
Sex comb on midleg like-2 is a novel specific marker for the diagnosis of gastroenteropancreatic neuroendocrine tumors
}

\author{
JIAO-JIAO YANG ${ }^{1 *}$, HUA HUANG $^{2 *}$, MING-BING XIAO ${ }^{1}$, FENG JIANG ${ }^{1}$, \\ WEN-KAI NI ${ }^{1}$, YI-FEI JI ${ }^{1}$, CUI-HUA LU ${ }^{1}$ and RUN-ZHOU NI ${ }^{1}$ \\ Departments of ${ }^{1}$ Gastroenterology and ${ }^{2}$ Pathology, Affiliated Hospital of Nantong University, \\ Nantong, Jiangsu 226001, P.R. China
}

Received October 10, 2016; Accepted April 21, 2017

DOI:10.3892/etm.2017.4677

\begin{abstract}
Sex comb on midleg like-2 (SCML2) is a polycomb-group protein that encodes transcriptional repressors essential for appropriate development in the fly and in mammals. On the basis of previous findings, the present study aimed to explore the possibility of developing SCML2 into a new diagnostic marker for gastroenteropancreatic neuroendocrine tumors (GEP-NETs). A total of 64 paired GEP-NET tissues and adjacent non-tumorous tissues were obtained from patients who had undergone surgical resection between January 2009 and January 2014, and the expression of SCML2 and two neuroendocrine markers, namely synaptophysin (Syn) and chromogranin A (CgA), in the tissues was assessed by immunohistochemistry. Strong SCML2 staining was observed predominantly in the cell nuclei of GEP-NET tissues, and the overall expression rate and staining intensity of SCML2 were higher than those of Syn or CgA, respectively. Spearman rank correlation analysis demonstrated that SCML2 was not correlated with either Syn or CgA, while the combined detection of SCML2 with Syn or with $\mathrm{CgA}$ increased the diagnostic sensitivity to $100 \%$. SCML2 expression in GEP-NETs was associated with several clinicopathological parameters, such as histological type, tumor grade, depth of invasion and clinical
\end{abstract}

Correspondence to: Professor Ming-Bing Xiao or Mr. Feng Jiang, Department of Gastroenterology, Affiliated Hospital of Nantong University, 20 Xisi Road, Nantong, Jiangsu 226001, P.R. China E-mail:xmb73@163.com

E-mail: jf6665@126.com

Abbreviations: SCM, sex comb on midleg; SCML2, sex comb on midleg like-2; GEP-NETs, gastroenteropancreatic neuroendocrine tumors; Syn, synaptophysin; CgA, chromogranin A; PcG, polycomb group

${ }^{*}$ Contributed equally

Key words: gastroenteropancreatic neuroendocrine, sex comb on midleg like-2, diagnosis, marker, immunohistochemistry stage. Kaplan-Meier survival curves revealed that patients with higher SCML2 expression had lower survival rates than those with lower expression levels, while Cox proportional hazards regression analysis revealed that SCML2 was not an independent prognostic factor for GEP-NET patients. Therefore, SCML2 may have potential as a specific marker for joint use with other markers to improve the diagnostic efficiency of GEP-NETs.

\section{Introduction}

Polycomb group (PcG) genes are required for maintenance of the correct spatial and temporal expression of homeotic genes during development (1). They were originally identified in Drosophila as transcriptional repressor genes, and subsequently have been detected in numerous vertebrates and invertebrates (1). Sex comb on midleg (SCM) is a PcG gene, and encodes transcriptional repressors required for appropriate development in flies and mammals (1-3). SCM is required for the recruitment and repressive function of polycomb repressive complex 1 (PRC1) and PRC2 (1), and contains two malignant brain tumor (MBT) repeats, a domain of unknown function (DUF3588), an SPM [also known as sterile $\alpha$ motif (SAM)] domain and two zinc fingers $(2,3)$. SCM exerts a repressive effect on target genes through the actions of MBT and SPM domains, as do other PcG proteins (4,5). Notably, abnormal SCM function may be involved in tissue growth and certain cancers (6).

The sex comb on midleg like-2 (SCML2) gene is one of the four homologs of Scm (the others being SCML1, SCM homolog 1 and SCM-like with four MBT domains) in mammals (7-11). SCML2 has been identified as a human gene in the $\mathrm{Xp} 22$ region that encodes a protein of 700 amino acids (7). In previous proteomic studies in which possible markers of pancreatic cancer were investigated (12-14), it was incidentally observed, by immunohistology, that the SCML2 protein was specifically expressed in human polypeptide hormone-producing tissues (pancreatic islet cells and islet-cell carcinoma), but was not expressed in other pancreatic epithelial cells. As a group, neuroendocrine tumors (NETs) secrete various different peptide hormones, and the aforementioned observation suggests that SCML2 could be a useful histologic marker for NETs. 
NETs are a heterogeneous group of tumors associated with a wide variety of biological changes occurring in the cells of the endocrine system (15). The molecular genetic mechanism by which NETs develop is complex and remains largely unknown (16). The majority of NETs were once considered carcinoid tumors, but recently the term 'neuroendocrine' has been accepted for use instead of 'carcinoid' to more appropriately describe the malignant potential of these tumors (17). Although NETs may develop in almost any organ of the body, they predominate within the pancreas and the gastrointestinal tract. Gastroenteropancreatic (GEP)-NETs are considered to be rare, with an incidence of 1 per 100,000 individuals for pancreatic tumors and 1.95-2.5 per 100,000 individuals for gastrointestinal tumors (15). During the last three decades, however, the reported incidence of GEP-NETs has increased worldwide due to improvements in diagnostic tools and clinical awareness of them (15). According to the latest 2010 World Health Organization (WHO) classification (18), GEP-NETs are divided into three types, namely well-differentiated NET, poorly differentiated neuroendocrine carcinoma and mixed adenoneuroendocrine carcinoma, and their pathology can be further graded as G1 [ $<2$ mitoses/10 high power fields (HPFs) and/or Ki-67 index $\leq 2 \%$ ], G2 (2-20 mitoses/10 HPFs and/or Ki-67 index between 3 and 20\%) and G3 ( $\geq 21$ mitoses/10 HPFs and Ki-67 index $>20 \%)(18-22)$.

Despite recent advances in the diagnosis and treatment of GEP-NETs, their early diagnosis remains challenging as the majority of patients lack typical symptoms (23). It is crucial to develop new markers that are comparable with and even better than currently available neuroendocrine markers, such as synaptophysin (Syn) and chromogranin $\mathrm{A}(\mathrm{CgA})$, for use in the diagnosis and prognosis of GEP-NETs. To contribute to the achievement of this goal, in the present study, SCLM2 expression in GEP-NETs was detected using immunohistochemistry, the diagnostic value of SCLM2 was compared with that of Syn or $\mathrm{CgA}$, and the correlations of SCLM2 with clinicopathological variables and with the prognosis of GEP-NETs were further investigated.

\section{Patients and methods}

Patients and tissue samples. A total of 64 paired tumor tissues and adjacent non-tumorous tissues were obtained from paraffin-embedded tissues of patients with GEP-NET (gastric, colorectal or pancreatic NET) who had undergone surgical resection at the Affiliated Hospital of Nantong University (Nantong, China) between January 2009 and January 2014 and had been evaluated and classified according to the WHO 2010 classification (18). The tumor grading of these cases was based on proliferation and mitotic count. Representative 1.5-2 mm tissue cores from each specimen were selected for immunohistochemistry. Personal information and clinicopathological data of the patients were obtained from electronic hospital records and pathology reports. Patients with a history of other cancers or who had received chemotherapy or radiotherapy prior to surgery were excluded from the present study. Follow-up information was collected by telephone interview or mail survey, and used for patient survival analysis. For all patients analyzed, the male/female ratio was $36: 28$, and the ages ranged from 17 to 86 years (median, 48 years). The personal information, clinical variables and pathological findings of the patients are summarized in Table I. In addition, the tissue samples of 10 gastric adenocarcinoma, 10 colorectal adenocarcinoma and 10 pancreatic adenocarcinoma cases, which had been histologically documented according to the WHO histological classifications of tumors, were used as controls. The present study was approved by the Ethics Committee of the Affiliated Hospital of Nantong University. Informed consent was obtained from all individual participants included in the study.

Immunohistochemistry. All paraffin-embedded tissue samples were fixed in $4 \%$ paraformaldehyde solution for $24 \mathrm{~h}$ at room temperature and embedded in paraffin, including 64 matched pairs of GEP-NET tissues and adjacent non-tumorous tissues, 10 gastric adenocarcinoma tissues, 10 colorectal adenocarcinoma tissues and 10 pancreatic adenocarcinoma tissues, were sectioned to 4- $\mu \mathrm{m}$ thickness and mounted on clean, charged microscope slides and then heated in a tissue-drying oven for $45 \mathrm{~min}$ at $60^{\circ} \mathrm{C}$. The sections were deparaffinized in xylene, rehydrated through graded alcohol, and then rinsed with deionized water. Endogenous peroxidase activity was quenched with $0.3 \%$ hydrogen peroxide for $10 \mathrm{~min}$ at room temperature and blocked with 5\% bovine serum albumin (BSA; Sigma-Aldrich; Merck KGaA, Darmstadt, Germany) in PBS for $20 \mathrm{~min}$ at room temperature. For antigen retrieval, the sections were heated for $30 \mathrm{~min}$ in a microwave oven in a preheated $0.01 \mathrm{M}$ citrate buffer ( $\mathrm{pH}$ 6.0, $\mathrm{C}_{6} \mathrm{H}_{8} \mathrm{O}_{7}, \mathrm{H}_{2} \mathrm{O} 0.378 \mathrm{~g}, \mathrm{Na}_{3} \mathrm{C}_{6} \mathrm{H}_{5} \mathrm{O}_{7}$, $2 \mathrm{H}_{2} \mathrm{O} 2.412 \mathrm{~g}$, and $\mathrm{ddH}_{2} \mathrm{O}$ to $1 \mathrm{l}$ ). The sections were incubated overnight at $4^{\circ} \mathrm{C}$ with mouse monoclonal antibodies against SCML2 (sc-271228), Syn (sc-398017) and CgA (sc-393941; all 1:200; Santa Cruz Biotechnology, Inc., Dallas, TX, USA) respectively. Afterwards, sections were further reacted with

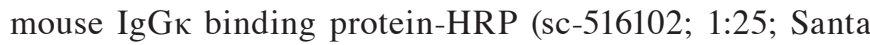
Cruz Biotechnology, Inc.) for $30 \mathrm{~min}$ at room temperature. Slides were stained with diaminobenzidine and counterstained with hematoxylin as described previously $(13,14)$. Sections were observed under a light microscope. The evaluation criteria of immunohistochemistry were as follows: Staining intensity was scored as 0 , negative; 1 , weak; 2 , medium; and 3 , strong; and staining extent was scored as 0,$0 ; 1,1-25 ; 2$, $26-50 ; 3,51-75$; and $4,76-100 \%$ according to the percentage of the positive staining areas in relation to the entire carcinoma area. The final result was expressed as the sum of the intensity score and the extent score, which was graded as: -, score 0-2; + , score 3 or $4 ;++$, score 5 or 6 ; and +++ , score 7 . Tumors with a final staining score of $\geq 3$ were considered positive. The immunohistochemical results were evaluated independently by two pathologists who were blinded to the patients' clinical and pathological data.

Statistical analysis. SPSS v15.0 software (SPSS Inc., Chicago, IL, USA) was used for statistical analysis. Materials with ranked data were tested with the rank sum test. The correlations between SCML2, Syn and CgA were tested by Spearman rank correlation. $\chi^{2}$ test or Fisher's exact test was used for any $2 \times 2$ tables. The association between clinical parameters and SCML2 expression was analyzed with a rank sum test. Survival analysis was performed using Kaplan-Meier survival plots, and comparisons between groups were made with the 
Table I. Associations of sex comb on midleg like-2 expression with clinicopathological parameters.

\begin{tabular}{|c|c|c|c|c|c|c|c|c|}
\hline \multirow[b]{2}{*}{ Parameters } & \multirow[b]{2}{*}{$\mathrm{n}$} & \multirow[b]{2}{*}{ Positive (\%) } & \multicolumn{4}{|c|}{ Grading } & \multirow[b]{2}{*}{$\mathrm{Z}$} & \multirow[b]{2}{*}{ P-value } \\
\hline & & & - & + & ++ & +++ & & \\
\hline Gender & & & & & & & 1.263 & 0.207 \\
\hline Male & 36 & $32(88.9)$ & 4 & 16 & 12 & 4 & & \\
\hline Female & 28 & $26(92.9)$ & 2 & 12 & 4 & 10 & & \\
\hline Age (years) & & & & & & & 0.551 & 0.582 \\
\hline$\leq 60$ & 38 & $34(89.5)$ & 4 & 16 & 12 & 6 & & \\
\hline$>60$ & 26 & $22(84.6)$ & 2 & 12 & 4 & 8 & & \\
\hline Tumor location & & & & & & & 0.400 & 0.690 \\
\hline Esophagus/stomach & 10 & $10(100.0)$ & 0 & 4 & 0 & 6 & & \\
\hline Intestine & 40 & $34(85.0)$ & 6 & 18 & 12 & 4 & & \\
\hline Pancreas & 14 & $14(100.0)$ & 0 & 6 & 4 & 4 & & \\
\hline Tumor diameter $(\mathrm{cm})$ & & & & & & & 0.501 & 0.616 \\
\hline$\leq 3$ & 50 & $44(88.0)$ & 6 & 20 & 14 & 10 & & \\
\hline$>3$ & 14 & $14(100.0)$ & 0 & 8 & 2 & 4 & & \\
\hline Pathological type & & & & & & & 2.370 & 0.020 \\
\hline NET & 36 & $30(83.3)$ & 6 & 18 & 8 & 4 & $3.254^{\mathrm{a}}$ & $0.001^{\mathrm{a}}$ \\
\hline NEC & 26 & $26(100.0)$ & 0 & 8 & 8 & 10 & & \\
\hline MANEC & 2 & $2(100.0)$ & 0 & 2 & 0 & 0 & & \\
\hline Pathological grade & & & & & & & 4.320 & $<0.001$ \\
\hline G1 & 24 & $18(75.0)$ & 6 & 14 & 4 & 0 & $3.103^{b}$ & $0.002^{\mathrm{b}}$ \\
\hline $\mathrm{G} 2$ & 14 & $14(100.0)$ & 0 & 6 & 4 & 4 & $4.277^{\mathrm{c}}$ & $<0.001^{\mathrm{c}}$ \\
\hline G3 & 26 & $26(100.0)$ & 0 & 8 & 8 & 10 & & \\
\hline Depth of invasion & & & & & & & 2.205 & 0.027 \\
\hline $\mathrm{T} 1-\mathrm{T} 2$ & 24 & $20(83.3)$ & 4 & 12 & 6 & 2 & & \\
\hline T3-T4 & 40 & $38(95.0)$ & 2 & 16 & 10 & 12 & & \\
\hline Lymph node metastasis & & & & & & & 1.798 & 0.072 \\
\hline Absent & 42 & $36(85.7)$ & 6 & 18 & 12 & 6 & & \\
\hline Present & 22 & $22(100.0)$ & 0 & 10 & 4 & 8 & & \\
\hline Distant metastasis & & & & & & & 0.684 & 0.494 \\
\hline Absent & 58 & $52(89.7)$ & 6 & 24 & 14 & 14 & & \\
\hline Present & 6 & $6(100.0)$ & 0 & 4 & 2 & 0 & & \\
\hline TNM stage & & & & & & & 2.698 & 0.007 \\
\hline I, II & 28 & $22(78.6)$ & 6 & 12 & 8 & 2 & & \\
\hline III, IV & 36 & $36(100.0)$ & 0 & 16 & 8 & 12 & & \\
\hline
\end{tabular}

${ }^{a}$ NET vs. NEC; ${ }^{b} \mathrm{G} 1$ vs. G2; ${ }^{\mathrm{c}} \mathrm{G} 1$ vs. G3. Z and P-values were calculated by rank sum test. NET, neuroendocrine tumor; NEC, neuroendocrine carcinoma; MANEC, mixed adenoneuroendocrine carcinoma.

log-rank test. Multivariate analysis was performed using Cox's proportional hazards model, and the risk ratio and its $95 \%$ confidence interval were recorded for each marker. $\mathrm{P}<0.05$ was considered to indicate a statistically significant result in all analyses.

\section{Results}

Expression of SCML2, Syn and CgA in paired GEP-NET tissues and adjacent non-tumorous tissues. Using immunohistochemistry (Fig. 1), strong SCML2 staining was observed predominantly in the cell nuclei of gastric, colorectal or pancreatic NET tissues (Fig. 1Aa-1, Aa-2, Ba-1, Ba-2, Ca-1 and $\mathrm{Ba}-2)$. By contrast, SCML2 staining was negative in the adjacent non-tumorous tissues of gastric- and colorectal-NET patients (Fig. 1 $\mathrm{Ab}$ and $\mathrm{Bb}$ ), and in gastric or colorectal adenocarcinoma tissues (Fig. 1Ac and Bc). Although SCML2 expression was low in islet cells, the final staining scores of SCML2 expression were negative (scores <3) in the adjacent non-tumorous tissues of patients with pancreatic 
Table II. Expression of SCML2, Syn and CgA in GEP-NETs ( $\mathrm{n}=64)$, adjacent non-tumorous tissues ( $\mathrm{n}=64)$ and adenocarcinoma tissues $(\mathrm{n}=30)$.

\begin{tabular}{|c|c|c|c|c|c|c|c|c|c|c|c|c|c|}
\hline \multirow[b]{2}{*}{ Marker } & \multicolumn{5}{|c|}{ GEP-NETs } & \multicolumn{4}{|c|}{$\begin{array}{l}\text { Adjacent non-tumorous } \\
\text { tissues }\end{array}$} & \multicolumn{4}{|c|}{ Adenocarcinoma } \\
\hline & Positive & - & + & ++ & +++ & - & + & ++ & +++ & - & + & ++ & +++ \\
\hline SCML2 & $58 / 64$ & 6 & 28 & 16 & 14 & 64 & 0 & 0 & 0 & 30 & 0 & 0 & 0 \\
\hline Syn & $54 / 64$ & 10 & 48 & 4 & 2 & 64 & 0 & 0 & 0 & 30 & 0 & 0 & 0 \\
\hline $\mathrm{CgA}$ & $46 / 64$ & 18 & 44 & 2 & 0 & 64 & 0 & 0 & 0 & 30 & 0 & 0 & 0 \\
\hline
\end{tabular}

In the GEP-NETs group: $\mathrm{Z}=4.179, \mathrm{P}<0.001$ for SCML2 vs. Syn; $\mathrm{Z}=5.449, \mathrm{P}<0.001$ for SCML2 vs. CgA; Z=2.073, $\mathrm{P}=0.038$ for Syn vs. CgA. $\mathrm{Z}$ and P-values were calculated by rank sum test. SCML2, sex comb on midleg like-2; Syn, synaptophysin; CgA, chromogranin A; GEP-NETs, gastroenteropancreatic neuroendocrine tumors; SCML2, sex comb on midleg like-2.
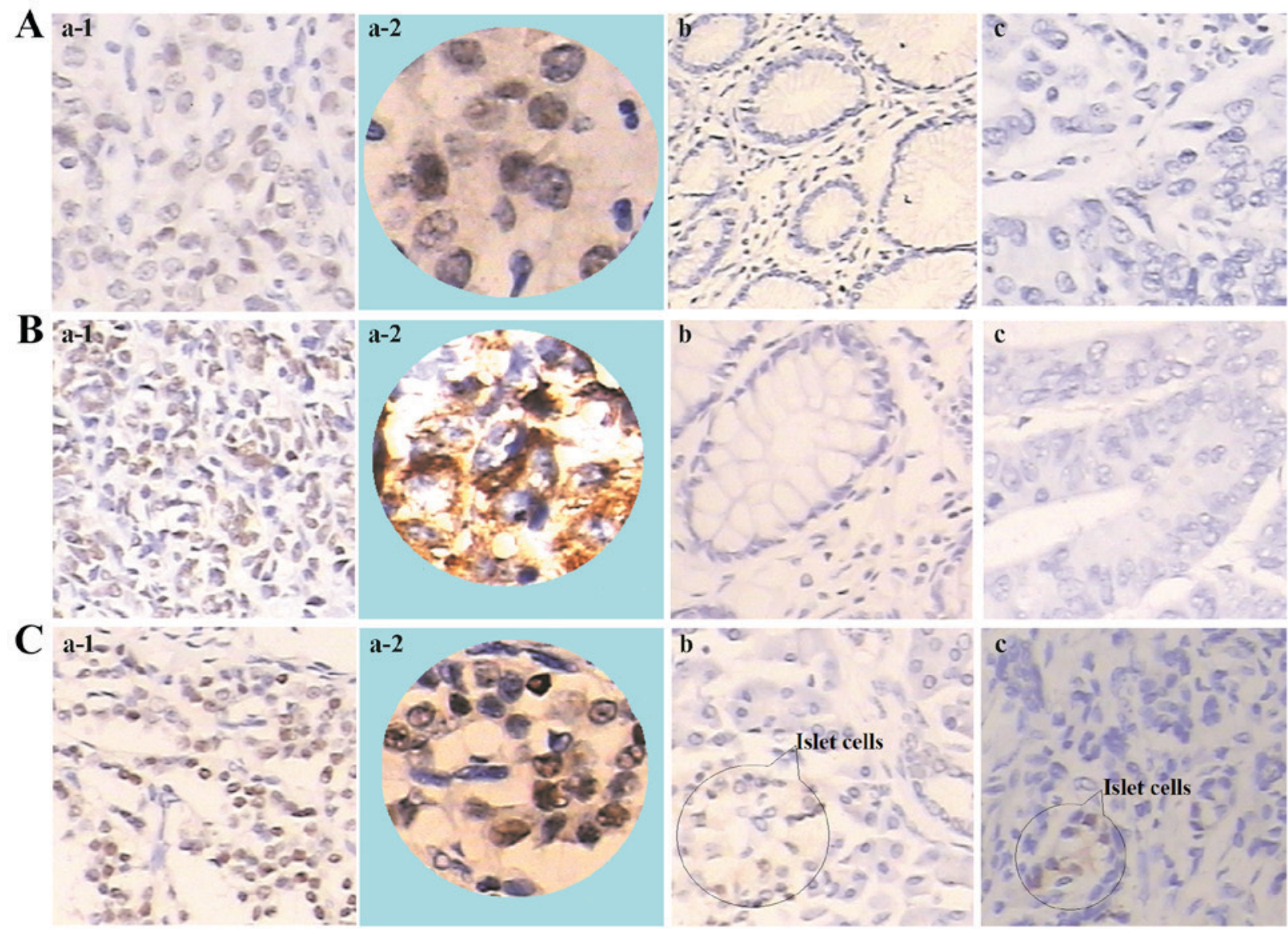

Figure 1. Immunohistochemical staining of SCML2 in gastroenteropancreatic neuroendocrine tumors, adjacent non-tumorous tissues and adenocarcinoma tissues. (A) Gastric tissues: Gastric neuroendocrine tumor tissue at (a-1) magnification, x200 and (a-2) magnification, x400, (b) adjacent non-tumorous tissue and (c) gastric carcinoma (both magnification, x200). (B) Colorectal tissues: Colorectal neuroendocrine tumor tissue at (a-1) magnification, x200 and (a-2) magnification, x400, (b) adjacent non-tumorous tissue and (c) colorectal carcinoma (both magnification, x200). (C) Pancreatic tissues: Pancreatic neuroendocrine tumor tissue at (a-1) magnification, x200 and (a-2) magnification, x400, (b) adjacent non-tumorous tissue and (c) pancreatic carcinoma (both magnification, x200). High expression of SCML2 detected in gastric, colorectal and pancreatic neuroendocrine tumors. No expression of SCML2 in the adjacent non-tumorous tissues of gastric and colorectal neuroendocrine tumors and in gastric and colorectal adenocarcinomas. Low expression of SCML2 in islet cells was detected; however, the final staining scores of SCML2 were negative $(<3)$ in the adjacent non-tumorous tissues of pancreatic neuroendocrine tumors and in pancreatic adenocarcinomas. SCML2, sex comb on midleg like-2.

NET (Fig. 1Cb) or pancreatic adenocarcinoma (Fig. 1Cc). Furthermore, staining of Syn and $\mathrm{CgA}$ was detected within the cytoplasm of NET cells (data not shown). Following a comparison of the staining results, it was noted that either the positive rate or the staining intensity of SCML2 [90.6\% $(58 / 64)$, more than half of which were graded ++ and +++$]$ was higher compared with that of Syn [84.4\% (54/64), the majority of which were graded +$]$ or than that of $\mathrm{CgA}[71.9 \%(46 / 64)$, 
Table III. Complementary value of SCML2, Syn and CgA in the diagnosis of gastroenteropancreatic neuroendocrine tumors.

\begin{tabular}{llcc}
\hline Marker & $\begin{array}{c}\text { Sensitivity } \\
(\%)\end{array}$ & $\begin{array}{c}\text { Specificity } \\
(\%)\end{array}$ & $\begin{array}{c}\text { Accuracy } \\
(\%)\end{array}$ \\
\hline SCML2 & $58 / 64(90.6)^{\mathrm{b}}$ & $94 / 94(100)$ & $152 / 158(96.2)^{\mathrm{b}}$ \\
Syn & $54 / 64(84.4)^{\mathrm{b}}$ & $94 / 94(100)$ & $148 / 158(93.7)^{\mathrm{b}}$ \\
CgA & $46 / 64(71.9)^{\mathrm{b}}$ & $94 / 94(100)$ & $140 / 158(88.6)^{\mathrm{b}}$ \\
SCML2 + Syn & $64 / 64(100)$ & $94 / 94(100)$ & $158 / 158(100)$ \\
SCML2 + CgA & $64 / 64(100)$ & $94 / 94(100)$ & $158 / 158(100)$
\end{tabular}

${ }^{\mathrm{a}}$ Final score $\geq 3 .{ }^{\mathrm{b}} \mathrm{P}<0.05$ for SCML2, Syn and CgA vs. (SCML2 + Syn) and (SCML2 $+\mathrm{CgA}$ ). Statistical analyses were performed by $\chi^{2}$ test or Fisher's exact test. SCML2, sex comb on midleg like-2; Syn, synaptophysin; $\mathrm{CgA}$, chromogranin A.

the majority of which were graded + ] in 64 GEP-NET samples $(\mathrm{Z}=4.179, \mathrm{P}<0.001$ and $\mathrm{Z}=5.449, \mathrm{P}<0.001$, respectively; Table II).

Complementary value of SCML2, Syn and CgA for diagnosis of GEP-NETs. Spearman rank correlation analysis was performed on the expression of SCML2, Syn and CgA. The results demonstrated that SCML2 was not correlated with either Syn $(r=0.2132, \mathrm{P}=0.091)$ or $\mathrm{CgA}(\mathrm{r}=0.0429, \mathrm{P}=0.736)$, suggesting that these three markers are complementary in the diagnosis of GEP-NETs. The sensitivity and accuracy of GEP-NET diagnosis significantly increased due to the combination of information on SCML2 and Syn or on SCML2 and CgA (Table III). The sensitivity and accuracy of each marker alone for the diagnosis of GEP-NETs was not high, but the combination of SCML2 with Syn or with CgA increased the sensitivity and accuracy to $100 \%$.

Associations of SCML2 expression with clinicopathological parameters in GEP-NETs. Correlation analysis between SCML2 expression and clinicopathological parameters (Table I) indicated that SCML2 expression was independent of patient gender, age, tumor location, tumor diameter, lymphatic or distant metastasis $(\mathrm{P}=0.207,0.582,0.690,0.616,0.072$ and 0.494 , respectively), but was significantly related to pathological type $(\mathrm{P}=0.020)$, pathological grade $(\mathrm{P}<0.001)$, depth of invasion $(\mathrm{P}=0.027)$ and TNM stage $(\mathrm{P}=0.007)$.

Survival analysis. At the end of follow-up, survival information was available for all patients. The overall survival time was a median of 1.42 years (range, 0.16-3.60 years), and 16 patients succumbed to tumor progression during follow-up (25.0\%). Univariate analysis for overall survival using the log-rank test revealed that age $(\mathrm{P}=0.003)$, pathological type $(\mathrm{P}<0.001)$, pathological grade $(\mathrm{P}<0.001)$, depth of invasion $(\mathrm{P}=0.014)$, lymph node metastasis $(\mathrm{P}<0.001)$, Syn expression $(\mathrm{P}<0.001), \mathrm{CgA}$ expression $(\mathrm{P}<0.001)$ or $\mathrm{SCML} 2$ expression $(\mathrm{P}=0.001)$ may serve as significant prognostic predictors. Kaplan-Meier survival curves demonstrated that

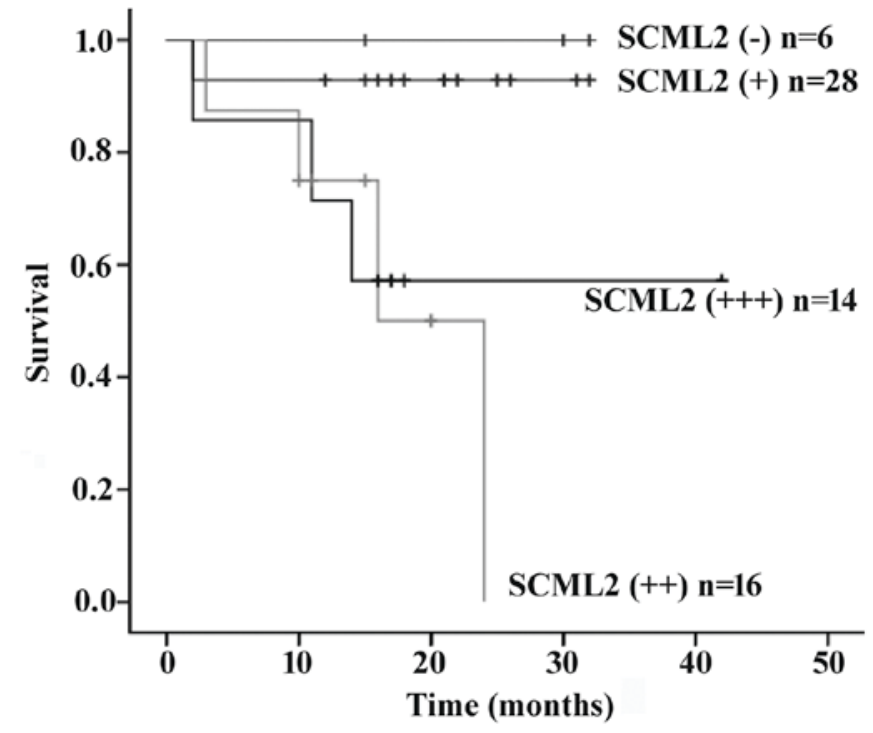

Figure 2. Kaplan-Meier survival curves showing the association between overall survival and SCML2 expression grading in 64 gastroenteropancreatic neuroendocrine tumor patients. SCML2, sex comb on midleg like-2.

SCML2 expression was associated with prognosis (Fig. 2). Multivariate analysis with the Cox proportional hazards model revealed that with the exception of age $(\mathrm{P}=0.006)$ and pathological grade $(\mathrm{P}=0.015)$, SCML2 $(\mathrm{P}=0.628)$ and other prognostic markers tested by univariate analysis were not independent predictors of the survival of patients with GET-NET (Table IV).

\section{Discussion}

SCML2 is a gene with homologies to the Drosophila $\mathrm{Scm}$ gene, and located in close proximity to SCML1, forming a gene cluster in $\mathrm{Xp} 22$; in primates, this gene cluster may have originated prior to primate divergence (9). SCML2 is specifically expressed in germ cells of mice, and loss of SCML2 reduces sperm production. SCML2 also regulates the epigenetic state of sex chromosomes during male meiosis (24-26). Human SCML2 gene encodes two protein isoforms: SCML2A (chromatin-bound) and SCML2B (nucleoplasmic). The former interacts with PRC1 and binds to non-coding RNAs in cultured immortal or cancer cells $(27,28)$, whereas the latter regulates the cell cycle by binding to cyclin-dependent kinase 2 (29). Accordingly, SCML2 plays a role in modulating the cell-cycle machinery and impacts the cellular activity when it is ectopically expressed in transformed or cancer cells $(28,29)$. In addition, there is evidence suggesting that SCML2 may be involved in human tumors, including malignant pediatric brain tumors, acute myeloid leukemia and human hepatocellular carcinoma (30-36). The above knowledge about SCML2, together with previous findings on SCML2 expression in islet-cell carcinoma (12-14), inspired the investigation of a more explicit linkage between SCML2 and GEP-NETs, a tumor with an increasing incidence worldwide, in the present study.

SCML2 expression was detected in GEP-NET tissues using immunohistochemical staining in the present study, and 
Table IV. Univariate and multivariate analyses of prognostic variables.

\begin{tabular}{|c|c|c|c|c|c|c|}
\hline \multirow[b]{2}{*}{ Variables } & \multicolumn{2}{|c|}{ Univariate $^{\mathrm{a}}$} & \multicolumn{4}{|c|}{ Multivariate $^{\mathrm{b}}$} \\
\hline & $\chi^{2}$ & P-value & Risk ratio & $95 \% \mathrm{CI}$ & $\mathrm{Z}$ & P-value \\
\hline Gender, male/female & 0.642 & 0.423 & - & - & - & - \\
\hline $\begin{array}{l}\text { Tumor location, } \\
\text { stomach/intestine/pancreas }\end{array}$ & 5.970 & 0.051 & - & - & - & - \\
\hline Tumor diameter, $\leq 3 />3 \mathrm{~cm}$ & 3.457 & 0.063 & - & - & - & - \\
\hline Distant metastasis, absent/present & 0.239 & 0.566 & - & - & - & - \\
\hline TNM stage, I,II/III,IV & 3.760 & 0.053 & - & - & - & - \\
\hline Age,$\leq 60 />60$ years & 8.733 & 0.003 & 13.976 & $2.128-91.786$ & 7.542 & 0.006 \\
\hline Pathological type, NET/NEC + MANEC & 15.678 & $<0.001$ & 0.216 & $0.024-1.974$ & 1.844 & 0.175 \\
\hline Pathological grade, G1/G2/G3 & 15.648 & $<0.001$ & 20.591 & $1.814-233.712$ & 5.956 & 0.015 \\
\hline Depth of invasion, T1,T2/T3,T4 & 6.040 & 0.014 & 0.393 & $0.035-4.395$ & 0.574 & 0.449 \\
\hline Lymph node metastasis, absent/present & 12.275 & $<0.001$ & 1.564 & $0.264-9.284$ & 0.243 & 0.622 \\
\hline Syn, $-/+/++/+++$ & 47.565 & $<0.001$ & 1.681 & $0.469-6.025$ & 0.637 & 0.425 \\
\hline $\mathrm{CgA},-/+/++/+++$ & 20.991 & $<0.001$ & 0.402 & $0.137-1.184$ & 2.731 & 0.098 \\
\hline SCML2, $-/+/++/+++$ & 16.271 & 0.001 & 0.824 & $0.378-1.799$ & 0.235 & 0.628 \\
\hline
\end{tabular}

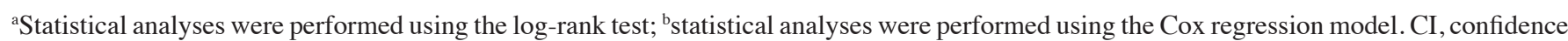
interval; NET, neuroendocrine tumor; NEC, neuroendocrine carcinoma; MANEC, mixed adenoendocrine carcinoma; Syn, synaptophysin; CgA, chromogranin A; SCML2, sex comb on midleg like-2.

then SCML2 was compared with existing markers in terms of diagnostic value. At present, GEP-NETs are commonly diagnosed by the immunostaining of Syn and $\mathrm{CgA}$, which are widely accepted as classic NET markers (37). In the present study, the positivity rates of Syn and CgA in GEP-NETs were calculated to be 84.4 and $71.9 \%$, respectively, and GEP-NET tissues exhibited weak positive staining with the majority of them being rated + . The results were essentially consistent with previously reported 76.19 and $72.62 \%$ positivity rates for Syn and CgA, respectively, in 168 cases of GEP-NET $(23,38)$. By contrast, it was noted in the present study that the positive rate of SCML2 in GEP-NETs was $90.6 \%$ and more than half of the staining intensity was graded ++ or +++ . Therefore, it could be suggested that SCML2 was at least comparable to Syn or CgA and even somewhat better than either of them for the diagnosis of GEP-NETs. Furthermore, Spearman rank correlation analysis indicated that SCML2 was not correlated with either Syn or $\mathrm{CgA}$, implying the three markers are complementary to one another for the diagnosis of GEP-NETs. The combined use of SCML2 with Syn or with $\mathrm{CgA}$ increased the diagnostic sensitivity and accuracy to $100 \%$. Therefore, the simultaneous detection of SCML2, Syn and CgA may be considered a preferred method for the diagnosis of GEP-NETs.

The present study also investigated the association between clinicopathological variables and the survival of patients. The results demonstrated that SCML2 expression was significantly correlated with pathological type, pathological grade, depth of invasion and TNM stage. Although Cox regression analysis revealed that age, pathological type, pathological grade, depth of invasion, lymph node metastasis, Syn expression, CgA expression and SCML2 expression were not independent unfavorable prognostic factors in GEP-NETs, they were consistently associated with survival time in GEP-NET cases, suggesting that SCML2 may play a role in the pathogenesis and development of GEP-NETs and its effect on survival time may be synergistic with that of other clinicopathological variables.

In summary, the present study provided original findings suggesting the potential of SCML2 as a valuable marker for GEP-NETs; however, the prognostic value of SCML2 may be poor because it is ubiquitously expressed in the majority of GEP-NETs. The joint use of SCML2 with Syn or CgA would clearly improve the diagnostic efficiency for GEP-NETs. Therefore, simultaneous measurement of SCML2 with Syn or $\mathrm{CgA}$ is recommended. Due to the limited number of tumor samples examined in the present study, the discriminating ability of markers was not validated, and further large-scale studies are required to gain an improved understanding of the role of SCML2 in GEP-NETs.

\section{Acknowledgements}

This study was supported by grants from the Natural Youth Science Foundation of China (grant no. 81502055), the Natural Science Foundation of Jiangsu Province (grant no. BK20161286), the Health Project of Jiangsu Province (grant no. H201624) and the Social Development Foundation of Nantong City (grant nos. MS22016056, MS22015062, HS2014072 and MS22015044). 


\section{References}

1. Wang L, Jahren N, Miller EL, Ketel CS, Mallin DR and Simon JA: Comparative analysis of chromatin binding by Sex Comb on Midleg (SCM) and other polycomb group repressors at a Drosophila Hox gene. Mol Cell Biol 30: 2584-2593, 2010.

2. Sathyamurthy A, Allen MD, Murzin AG and Bycroft M: Crystal structure of the malignant brain tumor (MBT) repeats in Sex Comb on Midleg-like 2 (SCML2). J Biol Chem 278 46968-46973, 2003.

3. Bornemann D, Miller E and Simon J: The Drosophila Polycomb group gene Sex comb on midleg $(\mathrm{Scm})$ encodes a zinc finger protein with similarity to polyhomeotic protein. Development 122: 1621-1630, 1996

4. Grimm C, de Ayala Alonso AG, Rybin V, Steuerwald U, Ly-Hartig N, Fischle W, Müller J and Müller CW: Structural and functional analyses of methyl-lysine binding by the malignant brain tumour repeat protein Sex comb on midleg. EMBO Rep 8: 1031-1037, 2007

5. Peterson AJ, Mallin DR, Francis NJ, Ketel CS, Stamm J, Voeller RK, Kingston RE and Simon JA: Requirement for sex comb on midleg protein interactions in Drosophila polycomb group repression. Genetics 167: 1225-1239, 2004.

6. Guo J and Jin D: A genetic screen in Drosophila implicates Sex comb on midleg $(\mathrm{Scm})$ in tissue overgrowth and mechanisms of Scm degradation by Wds. Mech Dev 136: 1-7, 2015.

7. van de Vosse E, Walpole SM, Nicolaou A, van der Bent P, Cahn A Vaudin M, Ross MT, Durham J, Pavitt R, Wilkinson J, et al: Characterization of SCML1, a new gene in Xp22, with homology to developmental polycomb genes. Genomics 49: 96-102, 1998.

8. Berger J, Kurahashi H, Takihara Y, Shimada K, Brock HW and Randazzo F: The human homolog of Sex comb on midleg (SCMH1) maps to chromosome 1p34. Gene 237: 185-191, 1999.

9. Montini E, Buchner G, Spalluto C, Andolfi G, Caruso A, den Dunnen JT, Trump D, Rocchi M, Ballabio A and Franco B: Identification of SCML2, a second human gene homologous to the Drosophila sex comb on midleg $(\mathrm{Scm})$ : A new gene cluster on Xp22. Genomics 58: 65-72, 1999.

10. Tomotsune D, Takihara Y, Berger J, Duhl D, Joo S, Kyba M, Shirai M, Ohta H, Matsuda Y, Honda BM, et al: A nove member of murine Polycomb-group proteins, Sex comb on midleg homolog protein, is highly conserved and interacts with RAE28/mph1 in vitro. Differentiation 65: 229-239, 1999.

11. Usui H, Ichikawa T, Kobayashi K and Kumanishi T: Cloning of a novel murine gene Sfmbt, Scm-related gene containing four mbt domains, structurally belonging to the Polycomb group of genes. Gene 248: 127-135, 2000.

12. Chen JH, Ni RZ, Xiao MB, Guo JG and Zhou JW: Comparative proteomic analysis of differentially expressed proteins in human pancreatic cancer tissue. Hepatobiliary Pancreat Dis Int 8: 193-200, 2009.

13. Xiao MB, Jiang F, Ni WK, Chen BY, Lu CH, Li XY and Ni RZ: High expression of S100A11 in pancreatic adenocarcinoma is an unfavorable prognostic marker. Med Oncol 29: 1886-1891, 2012.

14. Xie L, Ni WK, Chen XD, Xiao MB, Chen BY, He S, Lu CH Li XY, Jiang F and Ni RZ: The expressions and clinical significances of tissue and serum galectin-3 in pancreatic carcinoma. J Cancer Res Clin Oncol 138: 1035-1043, 2012.

15. Mia-Jan K, Munkhdelger J, Lee MR, Ji SY, Kang TY, Choi E and Cho MY: Expression of CD133 in neuroendocrine neoplasms of the digestive tract: A detailed immunohistochemical analysis. Tohoku J Exp Med 229: 301-309, 2013.

16. Öberg K: Genetics and molecular pathology of neuroendocrine gastrointestinal and pancreatic tumors (gastroenteropancreatic neuroendocrine tumors). Curr Opin Endocrinol Diabetes Obes 16: 72-78, 2009.

17. Gastrointestinal Pathology Study Group of Korean Society of Pathologists, Cho MY, Kim JM, Sohn JH, Kim MJ, Kim KM, Kim WH, Kim H, Kook MC, Park DY, et al: Current trends of the incidence and pathological diagnosis of gastroenteropancreatic neuroendocrine tumors (GEP-NETs) in Korea 2000-2009: Multicenter study. Cancer Res Treat 44: 157-165, 2012.

18. Jernman J, Välimäki MJ, Louhimo J, Haglund CJ and Arola J: The novel WHO 2010 classification for gastrointestinal neuroendocrine tumours correlates well with the metastatic potentia of rectal neuroendocrine tumours. Neuroendocrinology 95: $317-324,2012$
19. Kloppel G: Classification and pathology of gastroenteropancreatic neuroendocrine neoplasms. Endocr Relat Cancer 18 (Suppl 1): S1-S16, 2011.

20. Şahan EK, Erdoğan N, Ulusoy I, Samet E, İğdem AA and Gönüllü D: P53, KI-67, CD117 expression in gastrointestinal and pancreatic neuroendocrine tumours and evaluation of their correlation with clinicopathological and prognostic parameters. Turk J Gastroenterol 26: 104-111, 2015

21. Rindi G, Klöppel H, Alhman M, Caplin M, Couvelard A, de Herder WW, Erikssson B, Falchetti A, Falconi M, Komminoth $\mathrm{P}$, et al: TNM staging of foregut (neuro)endocrine tumors: A consensus proposal including a grading system. Virchows Arch 449: 395-401, 2006

22. Rindi G, Klöppel A, Couvelard P, Komminoth P, Körner M, Lopes JM, McNicol AM, Nilsson O, Perren A, Scarpa A, et al: TNM staging of midgut and hindgut (neuro) endocrine tumors: A consensus proposal including a grading system. Virchows Arch 451: 757-762, 2007.

23. Wang YH, Yang QC, Lin Y, Xue L, Chen MH and Chen J: Chromogranin A as a marker for diagnosis, treatment, and survival in patients with gastroenteropancreatic neuroendocrine neoplasm. Medicine (Baltimore) 93: e247, 2014.

24. Hasegawa K, Sin HS, Maezawa S, Broering TJ, Kartashov AV, Alavattam KG, Ichijima Y, Zhang F, Bacon WC, Greis KD, et al: SCML2 establishes the male germline epigenome through regulation of histone H2A ubiquitination. Dev Cell 32: 574-588, 2015.

25. Luo M, Zhou J, Leu NA, Abreu CM, Wang J, Anguera MC, de Rooij DG, Jasin M and Wang PJ: Polycomb protein SCML2 associates with USP7 and counteracts histone H2A ubiquitination in the XY chromatin during male meiosis. PLoS Genet 11: e1004954, 2015.

26. Lecona E, Narendra V and Reinberg D: USP7 cooperates with SCML2 to regulate the activity of PRC1. Mol Cell Biol 35: 1157-1168, 2015

27. Bezsonova I: Solution NMR structure of the DNA-binding domain from Scml2 (sex comb on midleg-like 2). J Biol Chem 289: 15739-15749, 2014.

28. Bonasio R, Lecona E, Narendra V, Voigt P, Parisi F, Kluger Y and Reinberg D: Interactions with RNA direct the Polycomb group protein SCML2 to chromatin where it represses target genes. Elife 3: e02637, 2014

29. Lecona E, Rojas LA, Bonasio R, Johnston A, FernándezCapetillo $O$ and Reinberg D: Polycomb protein SCML2 regulates the cell cycle by binding and modulating CDK/CYCLIN/p21 complexes. PLoS Biol 11: e1001737, 2013

30. Old LJ: Cancer/testis (CT) antigens- a new link between gametogenesis and cancer. Cancer Immun 1: 1, 2001.

31. Simpson AJ, Caballero OL, Jungbluth A, Chen YT and Old LJ: Cancer/testis antigens, gametogenesis and cancer. Nat Rev Cancer 5: 615-625, 2005.

32. Zendman AJ, Ruiter DJ and Van Muijen GN: Cancer/testis-associated genes: Identification, expression profile and putative function. J Cell Physiol 194: 272-288, 2003.

33. Branco MR, King M, Perez-Garcia V, Bogutz AB, Caley M, Fineberg E, Lefebvre L, Cook SJ, Dean W, Hemberger M and Reik W: Maternal DNA methylation regulates early trophoblast development. Dev Cell 36: 152-163, 2016.

34. Northcott PA, Nakahara Y, Wu X, Feuk L, Ellison DW, Croul S, Mack S, Kongkham PN, Peacock J, Dubuc A, et al: Multiple recurrent genetic events converge on control of histone lysine methylation in medulloblastoma. Nat Genet 41: 465-472, 2009.

35. Grubach L, Juhl-Christensen C, Rethmeier A, Olesen LH, Aggerholm A, Hokland P and Ostergaard M: Gene expression profiling of Polycomb, Hox and Meis genes in patients with acute myeloid leukaemia. Eur J Haematol 81: 112-122, 2008.

36. Qi L, Wang L, Huang J, Jiang M, Diao H, Zhou H, Li X and Jiang Z: Activated amelogenin Y-linked (AMELY) regulation and angiogenesis in human hepatocellular carcinoma by biocomputation. Oncol Lett 5: 1075-1079, 2013.

37. Wang Z, Li W, Chen T, Yang J, Luo L, Zhang L, Sun B and Liang R: Retrospective analysis of the clinicopathological characteristics of gastrointestinal neuroendocrine neoplasms. Exp Ther Med 10: 1084-1088, 2015.

38. Zhang X, Li M, Bao H, Zhang J, Wang Z and Gong P: Clinical, pathological and prognostic characteristics of gastroenteropancreatic neuroendocrine neoplasms in China: A retrospective study. BMC Endocr Disord 14: 54, 2014. 